\title{
(2) PRDتUCFF̄ ONLINE

\section{ANÁLISE DO PERFIL DOS ALUNOS DO PRIMEIRO CURSO DE EAD EM ENGENHARIA DE PRODUÇÃO EM INSTITUIÇÃO DE ENSINO SUPERIOR PÚBLICA}

\section{ANALYSIS OF THE PROFILES OF THE STUDENTS OF THE FIRST EAD COURSE IN PRODUCTION ENGINEERING IN THE INSTITUTION OF HIGHER PUBLIC EDUCATION}

\author{
Georgia de Souza Assumpção* E-mail: georgiasa@gmail.com \\ Priscila Carneiro Hamada* E-mail: pchamada@yahoo.com.br \\ Alexandre de Carvalho Castro*E-mail: o.aken@uol.com.br \\ *Centro Federal de Educação Tecnológica Celso Suckow da Fonseca (CEFET/RJ), Rio de Janeiro,
}

RJ

\begin{abstract}
Resumo: Dados sobre cursos superiores a distância, divulgados em estudos de órgãos oficiais brasileiros como o INEP, apontam um crescimento significativo do número de alunos e cursos nessa modalidade de Ensino a Distância. O curso de graduação a distância de Engenharia de Produção, proposta conjunta do CEFET/RJ, da UFF e do consórcio CEDERJ é uma nova iniciativa criada em meio a um cenário de expansão da demanda pela formação, expansão da modalidade de ensino, e o estímulo de órgãos como a CAPES e a ABENGE para ampliação do número de engenheiros no país. O presente artigo tem por objetivo analisar o perfil dos alunos do curso de Engenharia de Produção oferecido à sociedade pelo CEFET-RJ e UFF, através do consórcio CEDERJ, a partir do primeiro semestre de 2015. A metodologia qualitativa adotada no estudo permitiu elaborar um panorama geral sobre o ensino de Engenharia de Produção e o consórcio CEDERJ, uma descrição detalhada sobre o curso e sua estrutura básica. Através dos dados coletados no CEDERJ e no sistema de controle acadêmico do CEFET-RJ, foi realizada uma análise preliminar do perfil sociodemográfico dos alunos matriculados no curso. Foi possível perceber que o curso está atendendo majoritariamente a alunos do estado do Rio de Janeiro, oriundos de instituições públicas de ensino médio, do sexo masculino e com idade média de 30 anos.
\end{abstract}

Palavras-chave: Ensino a distância. Fatores humanos no trabalho. Engenharia de produção. CEDERJ e CEFET.

Abstract: Data on distance learning courses, published in studies of official Brazilian bodies such as INEP, point to a significant increase in the number of students and courses in this mode of distance education. The distance engineering course of Production Engineering, joint proposal of CEFET / RJ, UFF and the CEDERJ consortium is a new initiative created in the middle of a scenario of expansion of the demand for training, expansion of the teaching modality, and stimulus of organs such as CAPES and ABENGE to increase the number of engineers in the country. This article aims to analyze the profile of the students of the Production Engineering course offered to society by CEFET-RJ and UFF, through the CEDERJ consortium, from the first semester of 2015. The qualitative methodology adopted in the study allowed elaborating a panorama General about the teaching of Production Engineering and the CEDERJ consortium, a detailed description of the course and its basic structure. Through the data collected in CEDERJ and in the academic control system of CEFET-RJ, a preliminary analysis of the sociodemographic profile of the students enrolled in the course was performed. It was possible to perceive that the course is attending mainly to students of the state of Rio de Janeiro, coming from public institutions of high school, males and with average age of 30 years.

Keywords: Distance learning. Human factors at work. Production engineering. CEDERJ and CEFET. 


\section{INTRODUÇÃO}

A modalidade de curso de engenharia chamada de Engenharia de Produção pode ser considerada relativamente recente se comparada às demais modalidades de engenharia. De outra forma, podemos considerar uma origem mais remota para a Engenharia de Produção, a partir do momento em que o homem passou a preocupar-se não só com a produção, mas também com a organização, mecanização, integração, medida e aprimoramento dessa produção. É possível considerar-se a Revolução Industrial iniciada no século XVIII na Inglaterra como um marco significativo, com o aparecimento da manufatura introduzindo a máquinaferramenta, pois embora a prioridade tenha sido por melhorias tecnológicas, a busca da mecanização da produção acabou por introduzir processos de melhoria organizacional e de operações. (MELLO; TOZZI, 2010)

A formação em Engenharia de Produção desenvolveu-se primeiramente nos Estados Unidos e em alguns países da Europa, em finais do século XIX e início do século XX. Nos Estados Unidos, a paternidade da Engenharia de Produção é atribuída a Frederick Winslow Taylor. Já no Brasil, essa paternidade é atribuída ao professor Ruy Leme, pois foram dele as iniciativas de trazer, na segunda metade do século XX, a Engenharia de Produção para o país e implantá-la efetivamente na Universidade de São Paulo (USP). (MELLO; TOZZI, 2010)

De fato, a partir da experiência norte-americana, o ensino formal da então "Engenharia Industrial" somente veio a ser introduzida no Brasil na década de 1950, com a transição da nomenclatura para "Engenharia de Produção". No Rio de Janeiro, então capital do país, a Universidade Federal do Rio de Janeiro (UFRJ), passou a contar com conteúdos de Engenharia de Produção no curso de pósgraduação em Engenharia Econômica, no ano de 1957, ano em que também foi criado o primeiro curso em nível de graduação, na Escola Politécnica da Universidade de São Paulo, como opção do curso de Engenharia Mecânica. A partir de 1962, a Pontifícia Universidade Católica do Rio de Janeiro (PUC-Rio) incluiu seis disciplinas de Engenharia de Produção como opção da Engenharia Mecânica e, em 1964, como opção da Engenharia Metalúrgica (PIZZOLATTO, 1983 apud LEME, 1983). Em 1966, a mesma PUC-Rio criou o primeiro curso de Mestrado na área, logo seguida pela COPPE/UFRJ, que criou o seu em 1967. Cursos de Doutorado, 
por sua vez, foram organizados no ano de 1972, tanto na Escola Politécnica da Universidade de São Paulo quanto na COPPE/UFRJ.

O escopo da Engenharia de Produção implica a implantação e melhoria de sistemas produtivos a partir do envolvimento integrado de fatores humanos, recursos materiais e equipamentos, aspecto que implica prever e avaliar a eficácia e efetividade desses sistemas, com base em aportes da matemática, da física, das ciências humanas e sociais, em conjunto com princípios e métodos de análise da engenharia. Um estudo feito no início da década de 1990 (MORAIS et al, 1991), mostrou que naquela época, no Brasil, essa área já contava com 16 cursos de Graduação, 7 cursos de Mestrado e 3 de Doutorado (com a implantação do doutoramento na Universidade Federal de Santa Catarina).

Estudos feitos na década seguinte - anos 2000 - assinalaram que a partir de 1998 houve um expressivo desenvolvimento dos cursos de Engenharia de Produção no Brasil, ampliando o número dos 38 registrados em 1997 para aproximadamente 200 cursos de graduação em 2005 (FURLANETTO et al., 2006). Tal fenômeno de crescimento, vale lembrar, foi atribuído à época, tanto ao desenvolvimento do próprio país, quanto em função da formação multidisciplinar e visão sistêmica do engenheiro de produção, o que o tornava mais adequado a um mercado de trabalho que tinha demandas em diferentes áreas de uma organização produtiva: finanças, $P \& D$, recursos humanos, marketing e desenvolvimento de produtos.

No Centro Federal de Educação Tecnológica Celso Suckow da Fonseca (CEFET/RJ) o curso de Engenharia de Produção, na modalidade presencial, passou a ser oferecido à sociedade no ano de 1998. A partir do primeiro semestre do ano de 2015, o CEFET/RJ, juntamente com a Universidade Federal Fluminense (UFF) iniciou o oferecimento do primeiro curso a distância de Engenharia de Produção em Instituição de Ensino Superior pública, ofertado através do Consórcio CEDERJ (Centro de Educação Superior a Distância do Estado do Rio de Janeiro).

Segundo dados divulgados pelo Instituto de Pesquisa Econômica Aplicada (IPEA) em 2011, a demanda por engenheiros no mercado formal de trabalho em 2020 pode variar entre 600 mil e 1,4 milhão de profissionais, dependendo do nível de crescimento econômico do país. Apesar de alarmes terem sido divulgados no final da década de 2000 sobre a possibilidade de escassez generalizada desses profissionais baseados em cenários anteriores, os mesmos não se confirmaram, até 
por conta do crescimento econômico abaixo do esperado e do aumento da capacidade de o sistema de ensino superior formar os profissionais na área. Essa realidade, porém, não esgota a possibilidade de ocorrerem gargalos setoriais e regionais, seja por questões quantitativas de formação de profissionais para determinados setores ou regiões ou até qualitativas em relação a mão de obra formada (MACIENTE; NASCIMENTO, 2014).

Ainda que os dados de 2013 do Censo da Educação Superior do Ministério da Educação (MEC) tenham apontado um crescimento de $52 \%$ no número de matrículas nos cursos de Engenharia nos três últimos anos pesquisados, a proporção de alunos para cada 10 mil habitantes na área é aproximadamente um terço da registrada em outras áreas como Ciências Sociais, Administração e Direito. Como umas das ações para aumentar o número de profissionais formados em engenharia podem ser citados os esforços que a CAPES (Coordenação de Aperfeiçoamento de Pessoal de Nível Superior) e a ABENGE (Associação Brasileira de Educação de Engenharia) fizeram para retomar ações de estimulo às pesquisas científicas e tecnológicas e à formação de recursos humanos nesse segmento.

A partir do ano de 2007, a CAPES incluiu o fortalecimento das Engenharias no País como prioridade no Plano Nacional de Pós-Graduação 2005/2010. Em 2010, instituiu um Grupo de Trabalho, para propor ações de estímulo ao ingresso de estudantes nos cursos de graduação de Engenharias. Fomentou discussões e fóruns sobre a carência quantitativa e qualitativa de engenheiros no Brasil, com órgãos e entidades nacionais interessados no tema. Nos anos de 2012 e 2013, juntamente com a ABENGE, a CAPES retoma o Programa ProEngenharia, sob o lema "mais e melhores engenheiros", elegendo como um dos destaques os cursos EAD de graduação de Engenharia, enfatizando a modernização de práticas de laboratórios e de projetos e o estímulo ao uso das TIC nos processos pedagógicos. Dessa ação conjunta surge o Programa de Engenharia a Distância em Rede Nacional - UABEng, destinado à oferta por IES (Instituições de Ensino Superior) do Sistema UAB (Universidade Aberta do Brasil) de cursos de graduação nessa área, mediante edital de adesão em 2015 para início das atividades em 2016 (CLíMACO, 2015).

Sabe-se que até 2009, havia ocorrido uma forte expansão de ofertas de curso na área de Engenharia, Produção e Construção. Porém, após 2010, ocorreu uma 
significativa expansão de demandas por esses cursos, superando a oferta para o mesmo período (GUSSO; NASCIMENTO, 2014).

Os mais recentes dados sobre cursos superiores a distância, divulgados em estudos de órgãos oficiais brasileiros como o INEP, apontam um crescimento significativo do número de alunos e cursos nessa modalidade. Enquanto que nos primeiros anos a modalidade a distância no ensino superior estava voltada basicamente para a formação de profissionais ligados à área de educação, hoje é possível notar uma ampliação das áreas de concentração dos cursos, como é o caso da Engenharia de Produção. De fato, há novas iniciativas, como o curso de graduação a distância de Engenharia de Produção, proposta conjunta do CEFET/RJ, da UFF e do consórcio CEDERJ, que foi criado em meio a um cenário de expansão da demanda pela formação, expansão da modalidade de ensino, e o estímulo de órgãos como a CAPES e a ABENGE para ampliação do número de engenheiros no país.

O cenário apresentado até aqui, portanto, considera que tanto as atividades desenvolvidas por engenheiros estão intrinsecamente ligadas ao desenvolvimento econômico e à inovação, quanto o processo de formação de profissionais na área de Engenharia apresenta relevância para o futuro do Brasil. Nesse sentido, então, é que se configura o objetivo desta pesquisa, que consiste em analisar o perfil dos alunos do curso de Graduação em Engenharia de Produção do CEFET-RJ/UFF, mantido através do Consórcio CEDERJ.

\section{REVISÃO BIBLIOGRÁFICA DO CAMPO DE ESTUDOS}

Ao se proceder a uma revisão bibliográfica em portais de pesquisa (Periódicos Capes/Scielo/Scopus) com os descritores "CEDERJ" e "Engenharia de Produção" fica evidente a lacuna bibliográfica sobre esse tema, muito embora existam estudos sobre o CEDERJ sem se considerar a especificidade da formação de engenheiros de produção. Em linha gerais, há estudos sobre o CEDERJ, a partir de investigações de caráter censitário, que mostram o cumprimento da missão inicial de oferecer ensino público e gratuito em regiões não atendidas (ou pouco atendidas) pelas instituições públicas de Ensino Superior (CASSIANO et al, 2016). Há também, de modo genérico, estudos que avaliam os cursos a distância do CEDERJ nos 
âmbitos de áreas como a Pedagogia (GAMA; OLIVEIRA, 2006), a Física (CUNHA, 2006), a Matemática (SANTOS, 2013) e as Ciências Biológicas (MANTILLA et al., 2015),

Uma análise desse campo de estudos, contudo, focada especificamente nos domínios da EAD, permite caracterizar ainda mais a relevância desta pesquisa sobre o ensino de Engenharia de Produção em um curso a distância. Isso porque, em uma revisão de literatura realizada por Martins e Zerbini (2014), com o objetivo de traçar um panorama sobre os estudos realizados sobre educação a distância e cursos oferecidos via Internet, entre os anos 2000 e 2012, usando levantamento bibliográfico em bases de dados eletrônicas, é possível ver que apesar da existência de vários programas de EAD por todo o mundo, existe um descompasso considerável entre o número de publicações sobre aprendizagem e avaliação da efetividade destes. A conclusão desse estudo, aliás, indicou a necessidade de mais pesquisas sistemáticas que pudessem atestar a aplicabilidade da EAD, aspecto que põe em relevo a contribuição específica da presente pesquisa.

Essas mesmas autoras, em estudo mais recente (MARTINS; ZERBINI, 2015), relataram que apesar da crescente implantação da EAD, eram ainda muito embrionárias as avaliações efetivas da implantação de cursos no nível superior de ensino, particularmente no caso de cursos de graduação oferecidos a distância. As autoras reforçaram também que com o crescimento de cursos de graduação a distância desenvolvidos no país, é imperativo despender esforços em pesquisas cientificas que possam atestar a eficácia e qualidade da EAD, considerando a satisfação dos principais atores do processo, ou seja, os alunos.

Um outro dado a ser destacado é que a atenção com a formação de novos engenheiros para o mercado de trabalho é também importante e fundamental para permitir o desenvolvimento econômico e a inovação em um país. Nesse sentido, a OCDE (Organização de Cooperação e de Desenvolvimento Econômicos), organização internacional de economia com sede em Paris, nos alerta sobre o descompasso existente entre as habilidades ensinadas na escola e as competências requeridas pelas companhias atualmente, acrescentando que muitos países estão vivendo déficits de competências que estão diretamente afetando a atual, e futura, força de trabalho. (ROMANI, 2012). 
Em suma, cabe deixar claro que a contribuição acadêmica desta investigação, diante do estado da arte do campo de estudos, é a de apontar a EAD como alternativa válida em desenvolvimentos de projetos pedagógicos de cursos de Engenharia de Produção em um país continental como o nosso. Ou seja, tal contribuição para o campo consiste em dar uma série de aportes e subsídios, embasados em um estudo de caso, que podem vir a ser úteis na construção de futuros cursos de graduação à distância de acordo com as necessidades de formação de engenheiros de produção.

Nesse sentido, não cabe mais retornar a estados anteriores de análise, como na época em que se discutia sobre vantagens e desvantagens e acerca de prós e contras dessa modalidade de ensino a distância. $O$ que se põe efetivamente no horizonte de pesquisa é a necessidade de apontar caminhos e riscos de becos sem saída, visando à qualidade e aprimoramento dos cursos que vêm sendo oferecidos, considerando-os de fato como são: uma realidade já concretizada (ALMEIDA, 2016)

\section{O CONSÓRCIO CEDERJ}

A Fundação Cecierj (Centro de Ciências e Educação Superior a Distância do Estado do Rio de Janeiro) é um órgão vinculado à Secretaria de Estado de Ciência e Tecnologia (SECT) e desenvolve projetos nas áreas de Graduação a Distância através do Consórcio CEDERJ (Centro de Educação Superior a Distância do Estado do Rio de Janeiro). O CEDERJ foi criado no ano $2000 \mathrm{com}$ a finalidade de oferecer educação superior gratuita àqueles que moram no Estado do Rio de Janeiro, mas que não têm a oportunidade de frequentar uma instituição de ensino superior, seja pela distância de suas casas até as universidades ou mesmo por não disporem de tempo nos horários convencionais de aula. Atualmente, esse consórcio é composto por oito instituições públicas de ensino superior, sendo elas: CEFET-RJ (Centro Federal de Educação Tecnológica Celso Suckow da Fonseca), IFF (Instituto Federal de Educação, Ciência e Tecnologia Fluminense), UENF (Universidade Estadual do Norte Fluminense Darcy Ribeiro), UERJ (Universidade do Estado do Rio de Janeiro), UFF (Universidade Federal Fluminense), UFRJ (Universidade Federal do Rio de Janeiro), UFRRJ (Universidade Federal Rural do Rio de Janeiro) e UNIRIO (Universidade Federal do Estado do Rio de Janeiro). Inicialmente, oferecia 
ao público cursos de Licenciatura em diversas áreas de conhecimento e com 0 passar dos anos foi expandindo a oferta chegando, no ano de 2015, a 15 cursos de graduação a distância (FUNDAÇÃO CECIERJ, 2015).

O ingresso dos alunos em um dos cursos oferecidos pelo CEDERJ se dá mediante vestibular próprio ou utilização da nota do Enem (Exame Nacional do Ensino Médio). O percentual de vagas disponíveis por tipo de enquadramento no processo seletivo (ampla concorrência, Enem - ampla concorrência, Enem - ação afirmativa, cota ou professor da rede pública) varia de uma Instituição de Ensino Superior para outra.

A modalidade de ensino oferecida é semipresencial, obedecendo ao estabelecido pelo Decreto $\mathrm{n}^{0}$ 5.622/2005 que, em seu artigo quarto, trata da obrigatoriedade de avaliações de desempenho dos alunos através de exames presenciais (BRASIL, 2005).

Nos 32 polos CEDERJ espalhados pelo estado do Rio de Janeiro, são desenvolvidas atividades de laboratório, seminários e avaliações presenciais. $O$ candidato escolhe o polo a que ficará vinculado no ato de sua inscrição no vestibular. Além das atividades realizadas no polo, os alunos têm acesso a um Ambiente Virtual de Aprendizagem, também conhecido como Plataforma CEDERJ, onde são desenvolvidas todas as atividades a distância. Na Plataforma CEDERJ, estão disponíveis os materiais de estudo de cada uma das disciplinas do curso, as avaliações a distância, os cronogramas de atividades, ferramentas de comunicação e outras ações específicas da cada disciplina.

Os cursos do CEDERJ contam com tutores que não têm vínculo efetivo com a Fundação Cecierj, sendo bolsistas da área de pesquisa, selecionados através de análise de currículo, onde a titulação acadêmica e a experiência profissional são pontuadas e consideradas como muito relevantes (CECIERJ, 2016), razão pela qual muitos tutores são especialistas, mestres e doutores nas áreas dos cursos onde atuam.

Um dado importante que ajuda a configurar o atual contexto da instituição, entretanto, precisa ser indicado, uma vez que pode ter implicações futuras para o próprio consórcio CEDERJ. Em meados de 2015, o Estado do Rio de Janeiro começou a passar por uma crise fiscal, ainda que inicialmente pequena, causada em parte, segundo divulgado por próprios representantes do governo estadual, pelo não 
repasse de verbas dos royalties do petróleo (pré-sal). Em 2016, contudo, o cenário se agravou muito mais, pois com a redução orçamentária, a manutenção do prédio onde funcionava a Fundação CECIERJ ficou em condições precárias de funcionamento, tendo seus funcionários decidido inclusive por um movimento de greve por conta de ausência de manutenção dos elevadores, interrupção de serviços de limpeza, e falta de refrigeração ambiente. Movimento de paralização, aliás, acompanhado pelos tutores, pela falta de pagamento das bolsas. Com a mudança de instalações - a sede onde o CEDERJ funcionava foi transferida de um prédio no centro da cidade do Rio de Janeiro para outro, situado no bairro da Glória - a situação se estabilizou, em parte, mas há quem considere, com o agravamento da crise fiscal do estado, que podem ocorrer novas mudanças; talvez voltadas à privatização do processo de ensino ou à transferência do controle dos cursos de EAD para o governo federal.

\section{PANORAMA GERAL DO CURSO}

O curso de graduação a distância de Engenharia de Produção, do CEFET/RJ e UFF pelo consórcio CEDERJ, tem por objetivo possibilitar uma sólida formação nas áreas de conhecimento da Engenharia de Produção, de forma que os futuros engenheiros sejam capazes de atuar no planejamento, implantação, acompanhamento, manutenção, avaliação e melhoria de sistemas produtivos de bens e serviços, tomando em consideração os mais diversos aspectos, como os político-econômicos, sociais, ambientais e culturais, e preocupando-se em não se distanciar de uma visão ética e humanística. O curso é estruturado de maneira a se valorizar competências de uma formação tecnológica, de base matemática e computacional, com uma formação humanística (FUNDAÇÃO CECIERJ, 2015).

O curso apresenta uma matriz curricular com duração prevista de 10 semestres, podendo o aluno concluir até 0 limite de 15 semestres. $O$ aluno matriculado no curso, independentemente do polo CEDERJ a que estiver vinculado, cursará as mesmas disciplinas que os demais. No entanto, para concluir o curso e obter o diploma, além das disciplinas, o aluno deverá realizar o estágio supervisionado em empresa de sua escolha e apresentar um projeto final. Após cumprir todos esses requisitos, sua titulação será de Bacharel em Engenharia de 
Produção pela UFF ou Bacharel em Engenharia de Produção pelo CEFET/RJ, de acordo com o polo CEDERJ de origem.

A organização curricular está sintetizada na Figura 1, onde é possível verificar que as disciplinas que compõem o curso estão divididas em: núcleo de formação básica, núcleo de formação específica, estágio supervisionado e projeto final e atividades complementares.

Figura 1 - Organização curricular

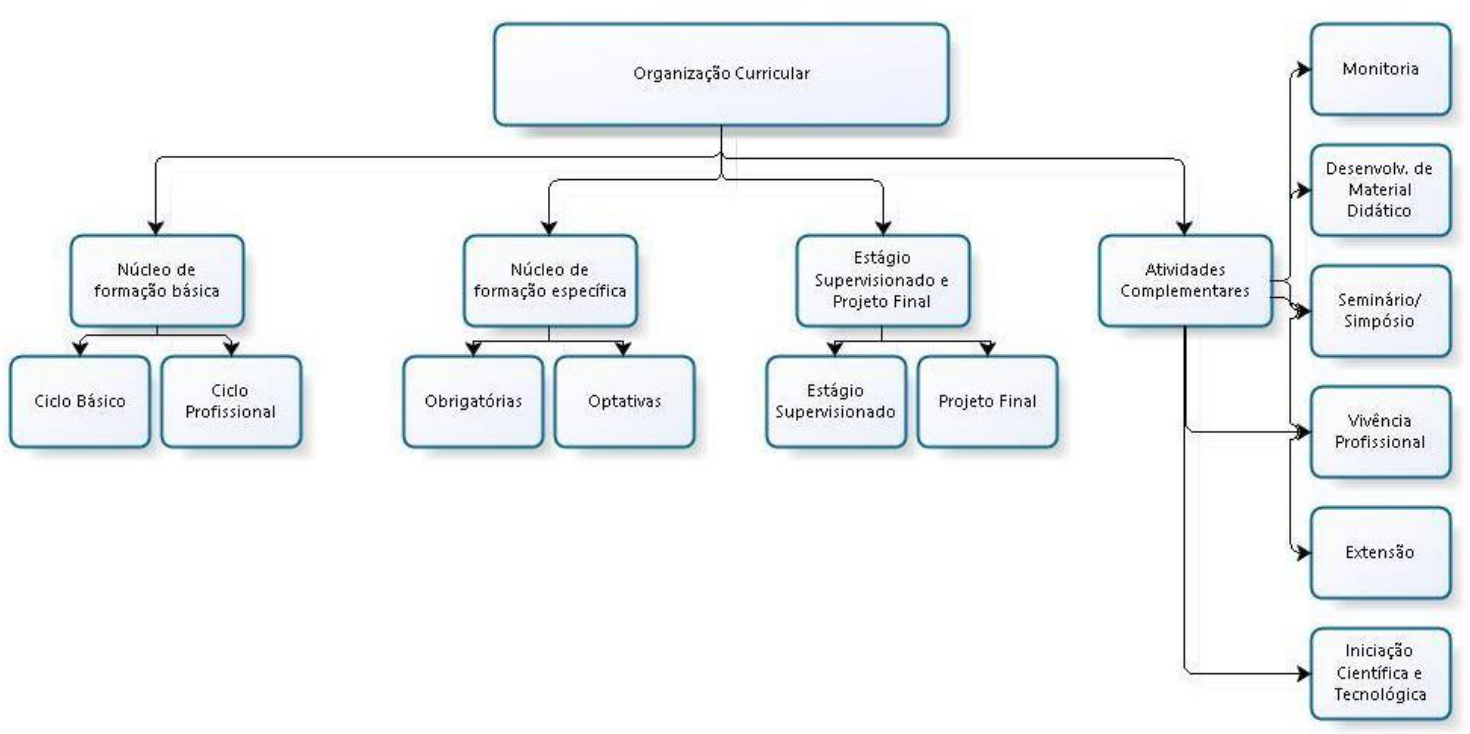

Fonte: Dados do Projeto Pedagógico do Curso (PPC)

No primeiro semestre de 2015, o curso foi oferecido em seis polos CEDERJ, sendo eles: Angra dos Reis, Itaperuna, Macaé, Piraí, Resende e São Gonçalo. No segundo semestre de 2015, dois novos polos passaram também a contar com 0 curso: Belford Roxo e Cantagalo. A seleção dos polos CEDERJ para a oferta do Curso de Engenharia de Produção levou em conta a estrutura de laboratórios já existente, principalmente dos cursos de física, química e biologia. Esse conjunto de laboratórios formam a estrutura capaz de suportar as atividades desenvolvidas pelos alunos ao longo do curso já que, de acordo com documento da ABEPRO (2008), os laboratórios para o núcleo de conteúdos básicos para os cursos de Engenharia de Produção devem possibilitar o desenvolvimento de conteúdos de física, química, informática, expressão gráfica, ciência e tecnologia dos materiais, cálculo numérico e fenômenos de transporte. 
Tabela 1 - Maiores Relações Candidatos/Vagas nos polos que oferecem o curso de Engenharia de Produção

\begin{tabular}{|c|c|c|c|c|c|c|c|c|c|}
\hline \multirow{2}{*}{ Polo } & \multirow{2}{*}{$\begin{array}{l}\text { Curso com maior } \\
\text { relação } \\
\text { candidato/vaga }\end{array}$} & \multicolumn{8}{|c|}{ Relação Candidato x Vaga } \\
\hline & & 2012-2 & 2013-1 & 2013-2 & 2014-1 & 2014-2 & 2015-1 & 2015-2 & 2016-1 \\
\hline \multirow{3}{*}{$\begin{array}{l}\text { Angra dos } \\
\text { Reis }\end{array}$} & Administração & 5,84 & 6,39 & 5,42 & & 4,42 & & & \\
\hline & $\begin{array}{l}\text { Engenharia de } \\
\text { Produção }\end{array}$ & & & & & & 19,14 & 10,1 & 7,96 \\
\hline & Pedagogia & & & & 5,13 & & & & \\
\hline \multirow{2}{*}{ Belford Roxo } & $\begin{array}{l}\text { Engenharia de } \\
\text { Produção }\end{array}$ & & & & & & & 18,90 & 14,30 \\
\hline & Pedagogia & 8,25 & 8,70 & 7,80 & 7,88 & 7,10 & 6,88 & & \\
\hline \multirow{3}{*}{ Cantagalo } & Administração & & & & & 3,63 & & & 3,69 \\
\hline & $\begin{array}{l}\text { Engenharia de } \\
\text { Produção }\end{array}$ & & & & & & & 6,70 & \\
\hline & Pedagogia & 5,35 & 5,40 & 5,15 & 4,65 & & 3,57 & & \\
\hline \multirow{4}{*}{ Itaperuna } & Administração & & & & & 2,36 & & & \\
\hline & $\begin{array}{l}\text { Engenharia de } \\
\text { Produção }\end{array}$ & & & & & & 5,66 & & 4,38 \\
\hline & Pedagogia & 6,25 & 5,95 & 4,50 & & & & & \\
\hline & $\begin{array}{l}\text { Tecnologia em } \\
\text { Segurança } \\
\text { Pública }\end{array}$ & & & & 5,96 & & & 5,1 & \\
\hline \multirow{3}{*}{ Macaé } & Administração & 10,25 & & 9,17 & & & & & \\
\hline & $\begin{array}{l}\text { Engenharia de } \\
\text { Produção }\end{array}$ & & & & & & 16,98 & 14,4 & 9,58 \\
\hline & Pedagogia & & 12,65 & & 9,05 & 7 & & & \\
\hline \multirow{4}{*}{ Piraí } & Administração & 4,44 & & 4,06 & 3,75 & & & & \\
\hline & $\begin{array}{l}\text { Engenharia de } \\
\text { Produção }\end{array}$ & & & & & & 12,40 & 8,20 & 6,66 \\
\hline & História & & & & & 3,08 & & & \\
\hline & Pedagogia & & 5,13 & & & & & & \\
\hline \multirow[b]{2}{*}{ Resende } & Administração & 5,91 & 6,19 & 5,43 & 5,09 & 4,72 & & & \\
\hline & $\begin{array}{l}\text { Engenharia de } \\
\text { Produção }\end{array}$ & & & & & & 10,32 & 6,90 & 5,82 \\
\hline \multirow[b]{2}{*}{ São Gonçalo } & Administração & 16,33 & 16,71 & 14,38 & 11,33 & 13,69 & & & \\
\hline & $\begin{array}{l}\text { Engenharia de } \\
\text { Produção }\end{array}$ & & & & & & 32,72 & 19,80 & 14,76 \\
\hline
\end{tabular}

Fonte: Adaptado de Relação Candidato/Vaga, disponível em http://cederj.edu.br/

Os alunos matriculados nos polos de Angra dos Reis, Cantagalo, Macaé e São Gonçalo serão diplomados pela UFF. Já os alunos matriculados em Belford Roxo, Itaperuna, Piraí e Resende terão seus diplomas expedidos pelo CEFET-RJ. A procura pelo curso de Engenharia de Produção oferecido pelo CEDERJ, já nos três primeiros semestres de oferta (2015.1 a 2016.1), vai ao encontro da tendência de expansão de demanda. A elevada relação candidato-vaga, destacando-se em relação aos demais cursos já ofertados pelo CEDERJ nos mesmos polos de apoio presencial, chama a atenção e desperta o interesse pelo estudo de suas características. Em praticamente todos os polos, a partir do momento em que o 
curso passa a ser oferecido, há um grande interesse, conforme pode ser visto na tabela 1. São relações candidatos-vagas significativamente maiores se comparadas às $s$ relações candidato-vagas de outros cursos em semestres anteriores.

Ao oferecer-se, à distância, um curso na área das Engenharias por Instituição de Ensino Superior Pública, é montado um cenário bem pouco conhecido e explorado, considerando-se o pequeno número de experiências semelhantes. E é dentro de tal cenário que se torna possível ressaltar a relevância do presente artigo, sobretudo por sua contribuição a fim de auxiliar à comunidade acadêmica com informações que possibilitam a análise do perfil dos alunos desse curso de graduação, frente às recorrentes necessidades de formação de profissionais aptos a atuar no mercado de trabalho de maneira efetiva.

\section{METODOLOGIA}

Um ponto importante referente ao método usado na pesquisa diz respeito à conjuntura em que o curso se encontrava quando foi pesquisado. As disciplinas então propostas para os três primeiros semestres (2015.1 a 2016.1) estavam ligadas principalmente ao núcleo de formação básica, conforme o Projeto Pedagógico do Curso (PPC), e nesse sentido estavam presentes no núcleo de formação básica comum à área de Engenharias, e seus materiais e conteúdos já estavam previamente desenvolvidos e sob a responsabilidade da UFF e/ou da UFRJ, no âmbito do consórcio CEDERJ. O CEFET/RJ era o responsável, segundo a matriz de disciplinas, por diversas disciplinas do núcleo de formação básica, ciclo profissional e também do núcleo de formação específica, que contribuem de forma mais perceptível para a construção do saber profissional aplicável dos alunos, mas algumas dessas disciplinas seriam ofertadas apenas a partir do quinto período do curso. O desenho metodológico do estudo, portanto, considerou que as informações estavam sendo conseguidas de modo dinâmico, uma vez que o curso podia experimentar pequenas mudanças ao longo do processo de pesquisa.

Assim, diante dessa conjuntura do curso, foi necessário lançar mão de um método que fosse, ao mesmo tempo, tanto viável quanto relevante. Isso porque a relevância deste estudo está no fato de permitir ressaltar as idas e vindas da implantação de um curso de EAD, variações essas que muitas vezes ficam 
invisibilizadas em circunstâncias nas quais há uma organização rígida e engessada de um curso ou processo de ensino.

Assim, a metodologia qualitativa desta pesquisa foi baseada em três etapas principais. Na primeira etapa foram realizadas entrevistas pessoais, com algumas perguntas abertas previamente elaboradas, com professores do CEFET-RJ envolvidos no projeto do curso, a fim de identificar seu contexto geral. Na segunda etapa, foi possível realizar entrevista pessoal, também através do uso de perguntas abertas previamente elaboradas, com representante do CEDERJ, com o objetivo de obter informações mais detalhadas sobre o Consórcio. A terceira etapa visou o levantamento do perfil dos alunos que se matricularam no curso, através dos seus dados sociodemográficos. Esse trabalho foi feito a partir de dados coletados nos sistemas de controle acadêmico dos polos sob a responsabilidade do CEFET-RJ, por questões de tempo e viabilidade. Os dados foram obtidos no mês de setembro de 2015, abrangendo dois semestres do ano de 2015 (2015.1 e 2015.2), com um total de 355 alunos matriculados.

\section{RESULTADOS DO LEVANTAMENTO DE DADOS}

Uma análise preliminar dos dados obtidos através do sistema acadêmico dos polos onde o curso de Engenharia de Produção está sob a responsabilidade do CEFET-RJ, permitiu a construção de alguns gráficos que oferecem um panorama geral do perfil dos alunos matriculados.

Conforme a figura 1, os alunos que residem no estado do RJ, onde ficam os polos do CEDERJ pesquisados, Belford Roxo, Piraí, Itaperuna e Resende, representam a grande maioria do total de alunos inscritos, chegando a $94 \%$ e $92 \%$ nos períodos 2015.1 e 2015.2, respectivamente. Os dados permitem verificar que o curso de Engenharia de Produção também está sendo realizado por alunos que residem em outros estados do país, sendo eles: Minas Gerais, São Paulo, Espírito Santo e Ceará. Observando-se o mapa do estado do Rio de Janeiro é possível ver que os polos de Itaperuna e Resende estão situados próximos à divisa dos estados de São Paulo, Minas Gerais e Espirito Santo, podendo ser essa uma das razões que levou alunos desses estados a buscar pelo curso. 
Figura 2 - Gráfico de Alunos por estado de residência - 2015.1 e 2015.2

ESTADOS DE RESIDÊNCIA

2015.1

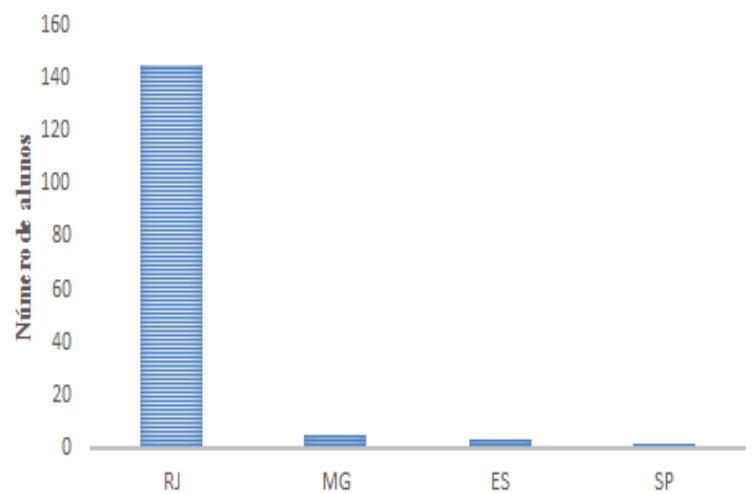

ESTADOS DE RESIDENNCIA 2015.2

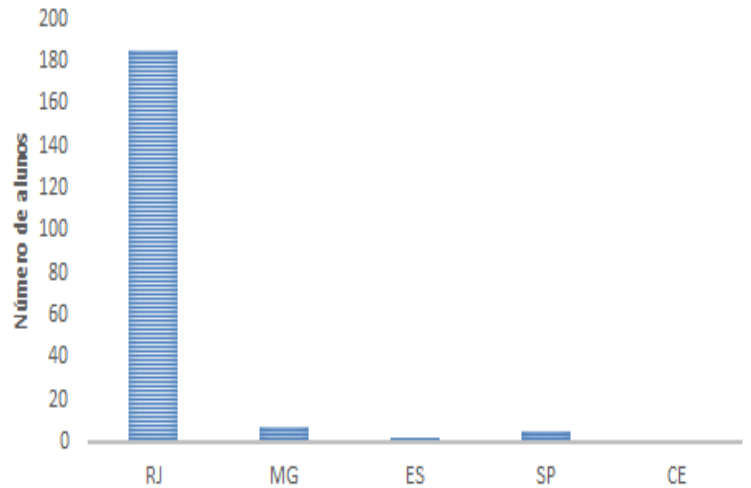

Fonte: Dados do sistema acadêmico do CEFET-RJ

A análise de alunos por municípios, permitiu verificar que estes estão distribuídos por um total de 68 municípios, incluindo-se municípios dos estados do Rio de Janeiro, Minas Gerais, Espirito Santo, São Paulo e Ceará. Os cinco municípios com maior número de alunos, representando somados $58,87 \%$ da população total de 355 alunos pesquisados, são: Rio de janeiro, com 81 alunos; Resende com 41 alunos; Volta Redonda, com 36 alunos; Campos dos Goitacazes, com 29 alunos e Itaperuna, com alunos 22 alunos. Os polos de Itaperuna e Resende são os que atendem aos maiores percentuais de alunos residentes em seus próprios municípios.

O perfil etário dos alunos é representado através da figura 2. As idades foram calculadas tomando-se como referência os valores da data de nascimento dos alunos e a primeira quinzena do mês de setembro de 2015. A média de idade é de 30,22 anos. A mediana da idade é 29 anos, a moda é 26 anos. 
Figura 3 - Perfil Etário dos alunos - 2015.1 e 2015.2

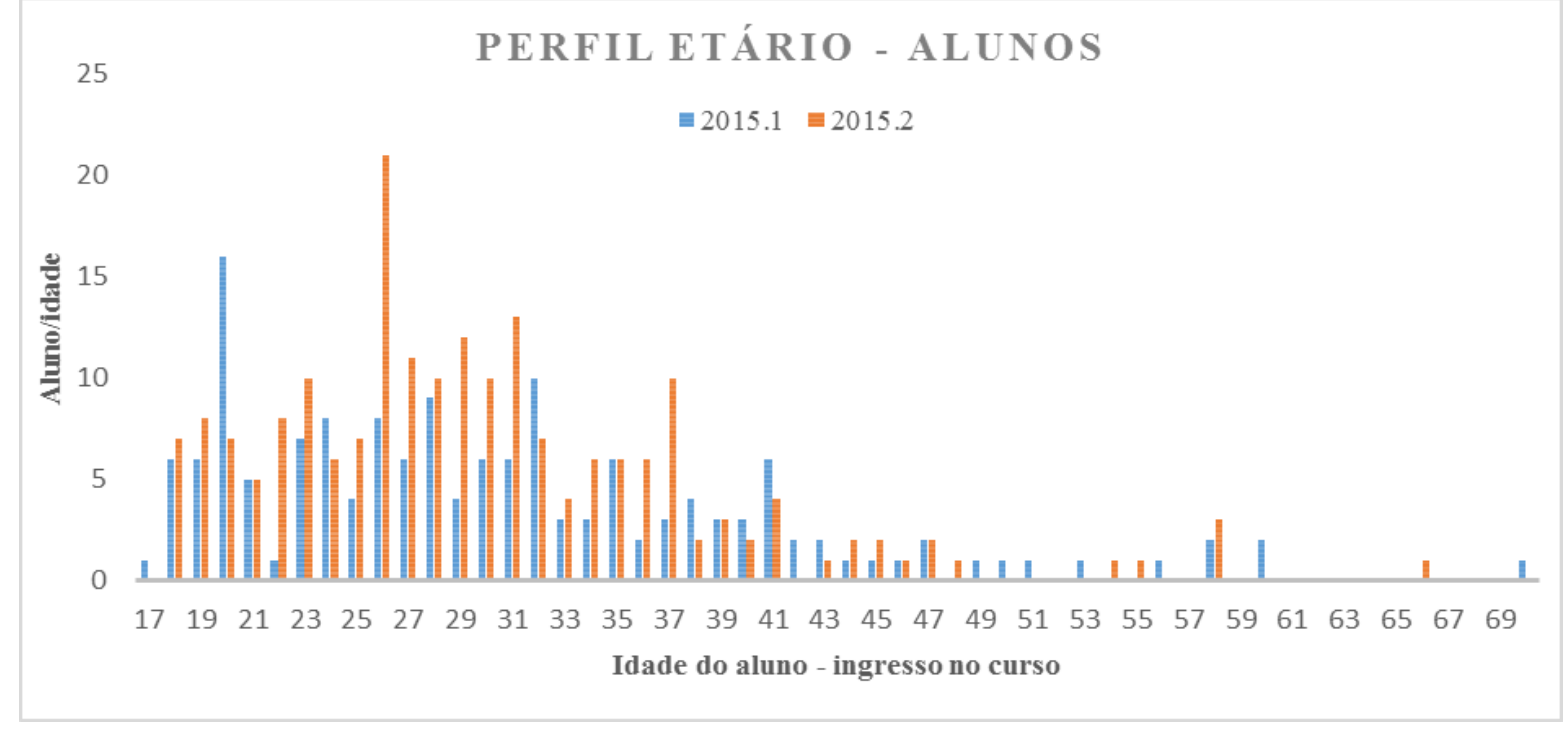

Fonte: Dados do sistema acadêmico do CEFET-RJ

Segundo dados do Resumo Técnico do Censo da Educação Superior (INEP, 2014), a participação feminina na educação superior supera a masculina. Em cursos a distância, a participação feminina é ainda maior. Contudo, nas áreas de Engenharia, Produção e Construção, a maioria dos alunos é de homens. A figura 3 mostra que os alunos são, em sua grande maioria, do sexo masculino, representando $72 \%$ e $77 \%$ dos ingressantes nos períodos 2015.1 e 2015.2 respectivamente.

Figura 4 - Alunos por gênero - 2015.1 e 2015.2

\section{ALUNOS POR GÊNERO \\ e Feminino $\equiv$ Masculino}

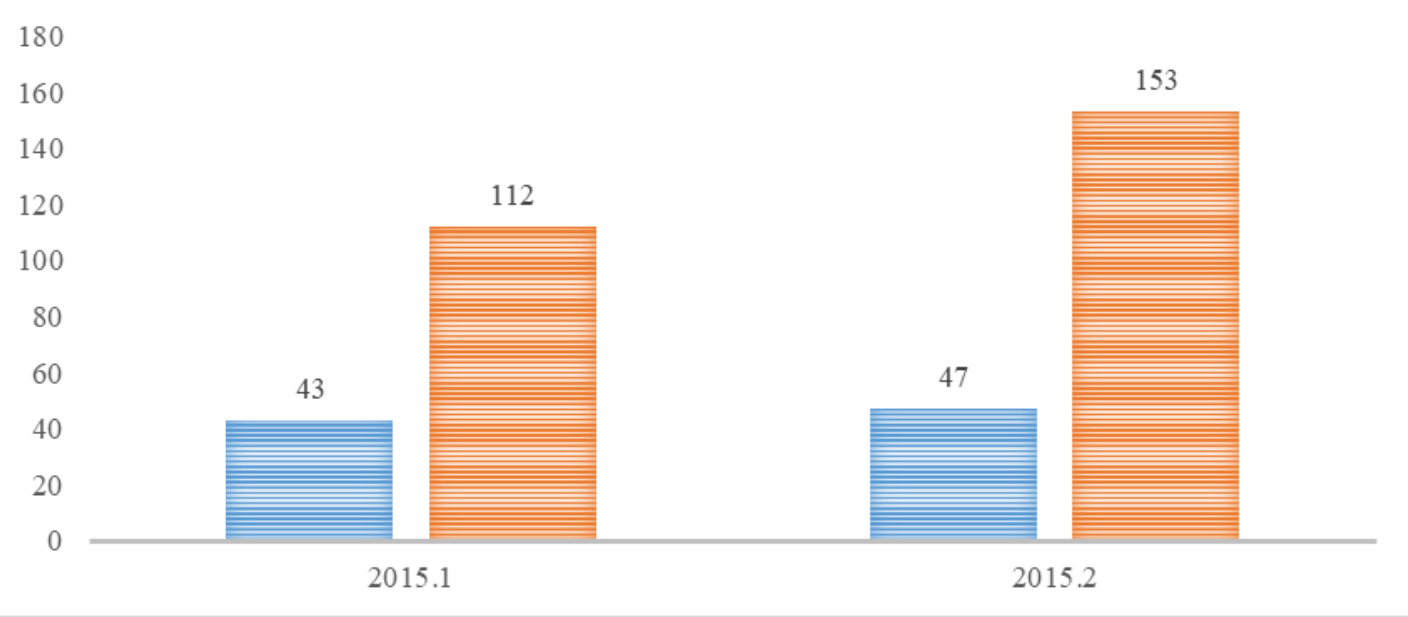

Fonte: Dados do sistema acadêmico do CEFET-RJ

Revista Produção Online. Florianópolis, SC, v. 18, n. 2, p. 404-423, 2018. 
Conforme mostram as figuras 4 e 5 , os alunos são egressos, majoritariamente, de instituições públicas, sendo as de âmbito Estadual mais numerosas dentre elas.

Figura 5 - Instituições de nível médio de origem dos alunos 2015.1 e 2015.2

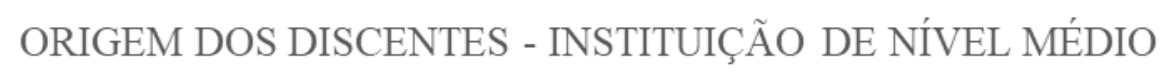

틀 2015.1 를 2015.2

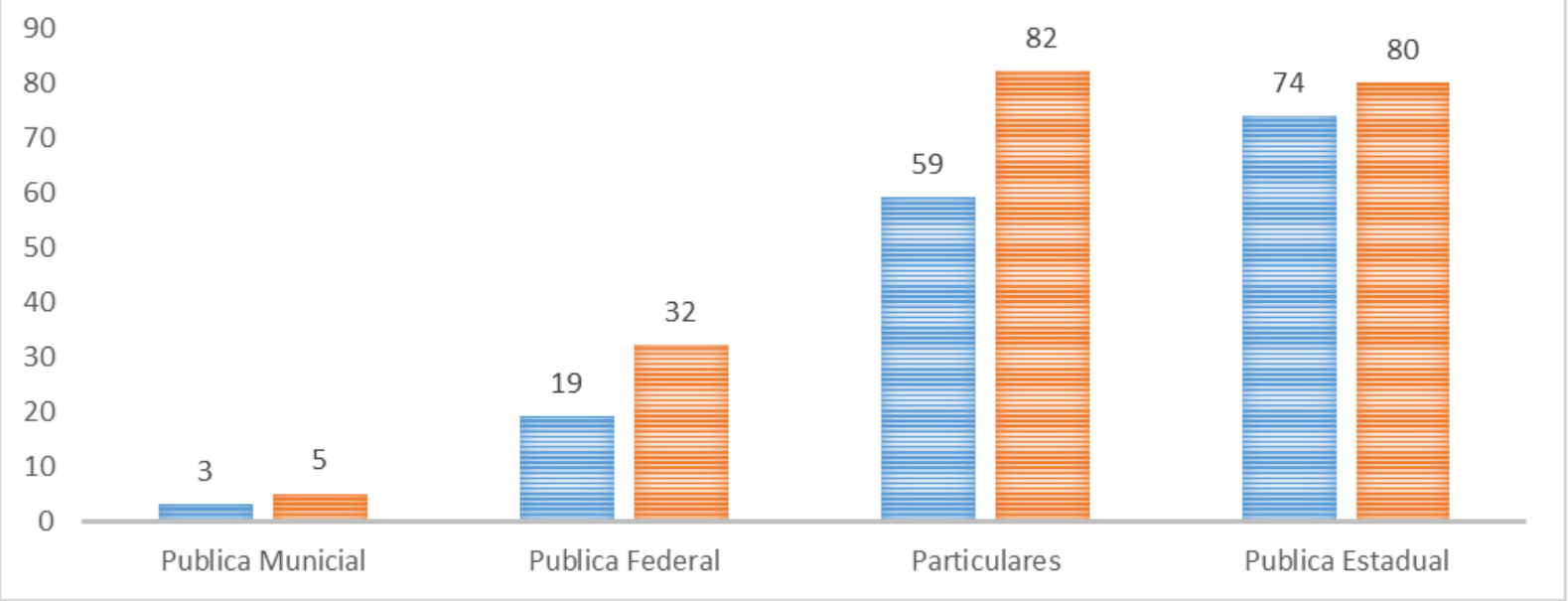

Fonte: Dados do sistema acadêmico do CEFET-RJ

Figura 6 - Instituições de nível médio de origem dos alunos 2015.1 e 2015.2

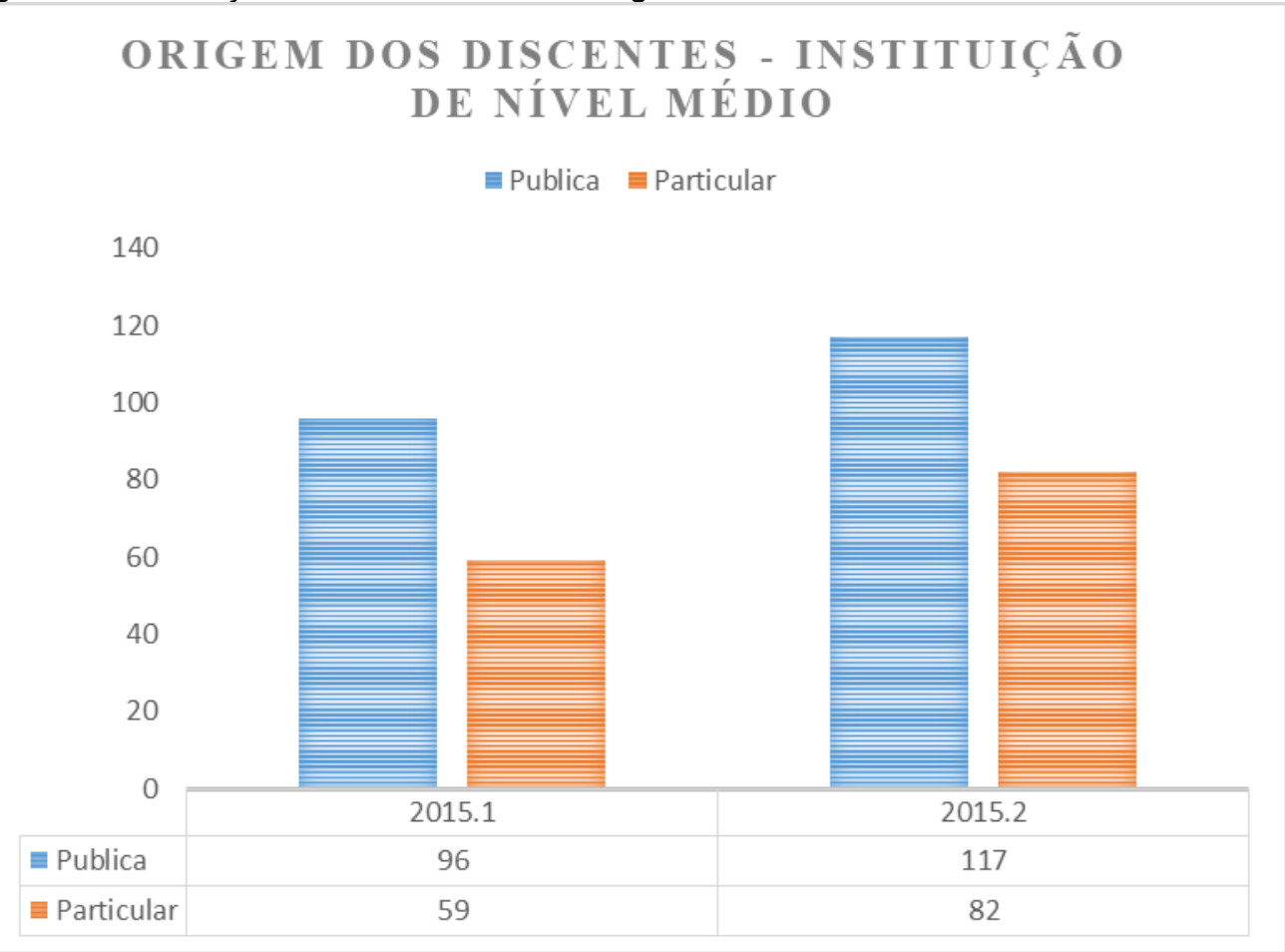

Fonte: Dados do sistema acadêmico do CEFET-RJ

Revista Produção Online. Florianópolis, SC, v. 18, n. 2, p. 404-423, 2018. 


\section{CONSIDERAÇÕES FINAIS}

O presente trabalho teve por objetivo geral analisar o perfil dos alunos do curso de Graduação em Engenharia de Produção do CEFET-RJ/UFF, mantido através do Consórcio CEDERJ. Buscou-se, nesse período de pesquisa, levantar informações relevantes para os estudos de cursos de graduação oferecidos a distância e, em especial, para o acompanhamento do desenvolvimento do projeto pedagógico proposto para o curso em análise. Dessa forma, espera-se contribuir com dados que auxiliem a construção de cursos orientados para as necessidades de formação de profissionais aptos a atuar no mercado de trabalho de maneira efetiva. Segundo Martins e Zerbini (2015), no Brasil, os cursos de graduação a distância vêm tendo um crescimento exponencial, sendo necessários nesse contexto, esforços despendidos por pesquisas cientificas para atestar sua eficácia e qualidade. Mas a área de avaliação de cursos no nível superior de ensino, especificamente, cursos de graduação ofertados a distância, é bastante incipiente. Dessa forma, o presente trabalho mostra-se relevante na medida em que pretendeu analisar o perfil dos alunos de um curso de graduação essencialmente a distância, em área de conhecimento das engenharias, oferecido conjuntamente por duas IES públicas, através de um consórcio de universidades públicas já com 16 anos de existência, em um momento bastante crítico para o Estado do Rio de Janeiro, que vem enfrentando duras dificuldades financeiras, que afetam principalmente áreas como a de educação.

O próprio projeto pedagógico do curso (PPC) explicita textualmente que um dos princípios básicos do Consórcio CEDERJ, é a manutenção da qualidade dos cursos das universidades consociadas, a fim de que apresentem o mesmo rigor acadêmico daqueles oferecidos de forma presencial. Assim sendo, uma das considerações que precisa ser feita, em função da atual conjuntura econômica, é a de alertar sobre os danos que uma possível descontinuidade de atividades e precariedade de infraestrutura oferecida nos polos CEDERJ poderão causar na formação dos alunos e na imagem que eles criam sobre a instituição e o curso que realizam, já que o polo presencial é a representação física das IES (CEFET-RJ/UFF) responsáveis pelo curso. 
Além disso, nessa mesma linha de análise, é interessante pensar sobre a própria atuação da Engenharia de Produção, que também segundo o projeto pedagógico do curso (PPC), abrange todos os campos onde se requer planejamento, coordenação e controle para que os recursos produtivos (fatores humanos, recursos materiais e equipamentos) sejam usados de forma integrada e racionalmente. Não seria interessante, então, avaliar os possíveis desenvolvimentos futuros do CEDERJ sob o crivo da própria Engenharia de Produção, em termos de otimização e controle de processos?

Ora, tais indagações e considerações decorrem diretamente do estudo que foi realizado e é, consequentemente, apresentado neste artigo. A fim de contextualizar adequadamente o cenário da pesquisa apresentou-se um panorama geral sobre o ensino de Engenharia de Produção e o consórcio CEDERJ, assim como uma descrição mais detalhada sobre o curso, sua estrutura básica, duração, e polos em que é oferecido; o que foi possível a partir das referências consultadas e também das informações levantadas através das entrevistas com profissionais envolvidos nesse projeto.

Através dos dados coletados no próprio CEDERJ e no sistema de controle acadêmico do CEFET-RJ, foi realizada uma análise do perfil sócio demográfico dos alunos matriculados nos dois primeiros semestres do curso. Foi possível perceber que o curso está atendendo majoritariamente a alunos do estado do Rio de Janeiro, oriundos de instituições públicas de ensino médio, e é composto principalmente por alunos do sexo masculino com idade média de 30 anos.

Este estudo, portanto, pretende contribuir de forma geral com futuras análises de perfil de alunos e demais estudos que possam auxiliar no aprimoramento de cursos à distância na área de Engenharia de Produção. Entretanto, mais uma vez vale ressaltar que as limitações desta pesquisa, centrada em um específico estudo de caso, impedem maior generalização dos resultados, o que, aliás, aponta a necessidade da realização de estudos futuros dentro dessa temática.

\section{REFERÊNCIAS}

ABEPRO. Laboratórios recomendados para o curso de Engenharia de Produção. Rio de Janeiro, 2008. Disponível em: 
<http://www.abepro.org.br/arquivos/websites/1/Laboratorios\%20Engenharia\%20de\%20Prod u\%C3\%A7\%C3\%A3o.pdf>. Acesso em: 28 jul. 2015.

ALMEIDA, H. R. F. L. Um Retrato de uma Licenciatura em Matemática a Distância sob a Ótica de seus Alunos Iniciantes. Bolema, Rio Claro, v. 30, n. 55, p. 857-861, ago. 2016. DOI: http://dx.doi.org/10.1590/1980-4415v30n55r02

BRASIL. Decreto no 5.622, de 19 de dezembro de 2005. Regulamenta o art. 80 da Lei no 9.394, de 20 de dezembro de 1996, que estabelece as diretrizes e bases da educação nacional. Diário Oficial [da] República Federativa do Brasil, Poder Executivo, Brasília, DF, 20 dez. 2005. Seção 1, p. 1.

CASSIANO, K. M. et al. Distribuição espacial dos polos regionais do Cederj: uma análise estatística. Ensaio: aval.pol.públ.Educ., Rio de Janeiro, v. 24, n. 90, p. 82-108, jan. /mar. 2016. Disponível em:< http://www.scielo.br/scielo.php?pid=S0104-

40362016000100082\&script=sci_abstract\&tlng=pt >. Acesso em: 05 mar. 2016. http://dx.doi.org/10.1590/S0104-40362016000100004

CLÍMACO, J. C. T. S. UABEng: educação a distância na graduação de Engenharia pelo Sistema Universidade Aberta do Brasil - CAPES. Brasília: CAPES, 2015. Disponível em: $<$ http://www.abenge.org.br/noticias/a-hrefhttp-www-abenge-org-br-figuras-uabeng-teatini-pdftarget_blankuabeng-educacao-a-distancia-na-gra>. Acesso em: 05 ago. 2015.

CUNHA, S. L. S. Reflexões sobre o EAD no ensino de física. Rev. Bras. Ensino Fís., São Paulo, v. 28, n. 2, p. 151-153, jun. 2006. DOI: http://dx.doi.org/10.1590/S0102$\underline{47442006000200005}$

FUNDAÇÃO CECIERJ. Consórcio CEDERJ. Disponível em: < http://cederj.edu.br/ cederj/>. Acesso em: 01 jul. 2015.

EDITAL Tutoria Distância (TD) 2016 - Cederj. Rio de Janeiro, 2016.

Disponível em: <http://cederj.edu.br/fundacao/wpcontent/uploads/2016/06/EDITAL-TD2016.pdf>. Acesso em: 25 out 2016.

FURLANETTO, E. L.; NETO, H. G. M.; NEVES, C. Engenharia de Produção no Brasil: reflexões acerca da atualização dos currículos dos cursos de graduação. Revista Gestão Industrial, Curitiba, v. 2, n. 4, 2006. DOI: http://dx.doi.org/ 10.3895/S1808-

04482006000400004

GAMA, Z. J.; OLIVEIRA, E. S. G. A avaliação da aprendizagem: a proposta do curso de Pedagogia a distância do Consórcio CEDERJ. In: SILVA, M.; SANTOS, E. (Orgs.)

Avaliação da aprendizagem em educação online. São Paulo: Edições Loyola, 2006. p. 449- 460 .

GUSSO, D. A.; NASCIMENTO, P. A. M. M. Evolução da Formação de Engenheiros e Profissionais Técnico - Científicos no Brasil entre 2000 e 2012. In: OLIVEIRA, M. P. P. (Org.) et al. Rede de pesquisa "Formação e mercado de trabalho": coletânea de artigos. Brasília: Ipea; ABDI, 2014. v.4, cap. 1, p. $17-60$.

INEP. Censo da educação superior 2012: resumo técnico. Brasília: Instituto Nacional de Estudos e Pesquisas Educacionais Anísio Teixeira, 2014.

LEME, R. A. S. História de engenharia de produção no Brasil. São Paulo: mimeo, 1983. Não paginado. 
MACIENTE, A.N.; NASCIMENTO, P. A. M. M. A demanda por engenheiros e profissionais afins no mercado de trabalho formal. In: OLIVEIRA, M. P. P. (Org.) et al. Rede de pesquisa "Formação e mercado de trabalho": coletânea de artigos. Brasília: Ipea; ABDI, 2014. v. 4, cap. 3, p. $99-134$.

MANTILLA, S. P. S. et al. Recursos Educacionais Abertos para o Curso de Ciências Biológicas do Consórcio Cederj: Produção, Uso e Disponibilização. EaD em FOCO, [S.I.], v. 5, n. 1, jan. 2015. DOI: http://dx.doi.org/10.18264/eadf.v5i1.305

MARTINS, L. B.; ZERBINI, T. Educação a distância em instituições de ensino superior: uma revisão de pesquisas. Revista Psicologia: Organizações e Trabalho, Florianópolis, v. 14, n. 3, p. 271-282, jul./set. 2014. Disponível em: < http://pepsic.bvsalud.org/scielo.php?script=sci arttext\&pid=S1984-

$66572014000300003 \&$ lng=pt\&nrm=iso >. Acesso em: 20 ago. 2016.

Evidências de validade de instrumentos de reações no ensino superior à

distância. Estud. pesqui. psicol., Rio de Janeiro , v. 15, n. 1, p. 116-134, abr. 2015.

Disponível em <http://pepsic.bvsalud.org/scielo.php?script=sci_arttext\&pid=S1808-

$42812015000100008 \&$ Ing=pt\&nrm=iso >. Acesso em: 20 jan. 2016.

MELLO, E. D. (Coord.); TOZZI, M. J. (Coord). Trajetória e estado da arte da formação em Engenharia, Arquitetura e Agronomia - volume II. Brasília: Instituto Nacional de Estudos e Pesquisas Educacionais Anísio Teixeira; Conselho Federal de Engenharia, Arquitetura e Agronomia, 2010.

MORAIS, A. et al. Avaliação e perspectivas em ciência e tecnologia na área de engenharia de produção. Prod., São Paulo, v. 1, n. 1, p. 23-39, jun. 1991.

DOI: http://dx.doi.org/10.1590/S0103-65131991000100002

ROMANI, C. C. Explorando tendências para a educação no Século XXI. Cad. Pesqui., São Paulo, v. 42, n. 147, p. 848-867, dez. 2012. Disponível em:

$<$ http://www.scielo.br/scielo.php?script=sci_arttext\&pid=S010015742012000300011\&lng=en \&nrm=iso >. Acesso em: 10 abr. 2016. http://dx.doi.org/10.1590/S0100-15742012000300011

SANTOS, S. C. Um Retrato de uma Licenciatura em Matemática a Distância sob a ótica de seus Alunos Iniciantes. 2013. 208 p. Tese (Doutorado em Educação Matemática) Instituto de Geociências e Ciências Exatas, Universidade Estadual Paulista, Rio Claro, 2013. DOI: http://dx.doi.org/10.1590/1980-4415v30n55r02

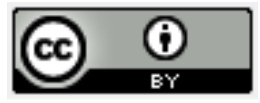

Artigo recebido em 02/03/2017 e aceito para publicação em 10/10/2017

DOI: http://dx.doi.org/10.14488/1676-1901.v18i2.2757 